\title{
Suzuki and Heck reactions promoted by an ionically-tagged palladium complex
}

\author{
Marcelo R. dos Santos ${ }^{\star a}$, Adriano L. Monteiro ${ }^{b}$ and Brenno A. D. Neto ${ }^{a}$ \\ a Laboratory of Medicinal and Technological Chemistry, Institute of Chemistry - Brasilia University (UnB), DF. \\ ${ }^{b}$ Laboratory of Molecular Catalysis, Institute of Chemistry - UFRGS, RS . \\ *marcelotigre@gmail.com
}

Keywords: Suzuki coupling, Heck reaction, ionically-tagged.

\section{INTRODUCTION}

Ionic liquids (ILs) are regarded as a great media for organometallic catalysis. It has been recently reviewed that the use of modified catalysts, which incorporate an ionic tag such as the imidazolium ring, may comprise a promising solution for the problem of catalyst leaching. ${ }^{1}$ In this sense, we describe herein a novel ionically-tagged palladium catalyst and its application in C-C bond formation.

\section{RESULTS AND DISCUSSION}

The novel ionically-tagged palladium complex was synthesized as described in Scheme 1.
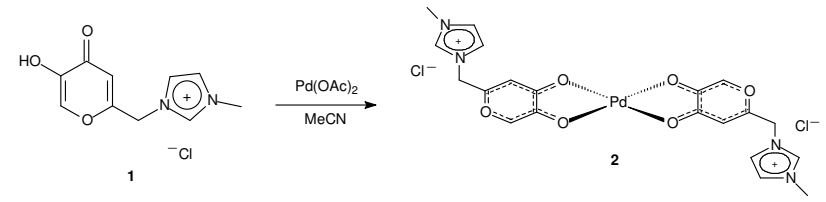

Scheme 1. Synthesis of the ionically-tagged palladium complex.

The palladium catalyst was applied in Suzuki and Heck reactions of several aryl halides (Scheme 2).
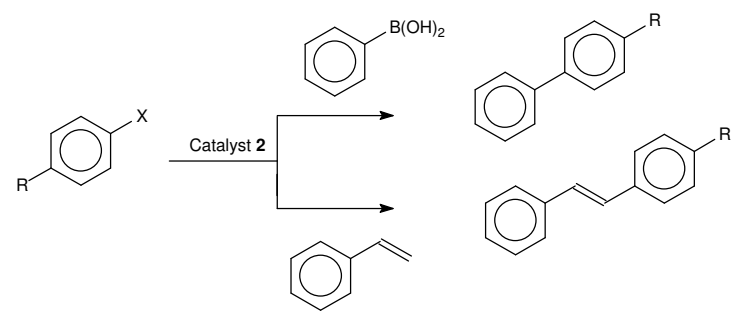

Scheme 2. Suzuki coupling and Heck arylation promoted by palladium catalyst 2 .

Table 1 shows some results for the Suzuki and Heck reactions under different conditions. All yields in DMF were excellent, both Heck and Suzuki reactions. Nevertheless, the use of ILs gave only modest yields. Studies are underway in order to optimize yields in ILs and carry out recycling reactions.
Table 1. Yields for the Suzuki and Heck reactions.

\begin{tabular}{|c|c|c|c|c|}
\hline Entry & ArX & Reaction* & medium & Yield(\%) \\
\hline 1 & 4- & Suzuki & DMF & 85 \\
\hline 2 & 4- & Suzuki & DMF & 76 \\
\hline 3 & Phi & Suzuki & DMF & 100 \\
\hline 4 & $\mathrm{PhBr}$ & Suzuki & DMF & 100 \\
\hline 5 & $4-\mathrm{NO}_{2} \mathrm{Phl}$ & Suzuki & DMF & 100 \\
\hline 6 & 4- & Suzuki & DMF & 100 \\
\hline $7^{a}$ & $4-$ & Suzuki & DMF & 100 \\
\hline 8 & $4-^{-}$ & Suzuki & $\mathrm{BMI} \cdot \mathrm{BF}_{4}{ }^{\mathrm{D}}$ & 22 \\
\hline 9 & 4- & Suzuki & $\mathrm{BMI} \cdot \mathrm{BF}_{4}{ }^{\mathrm{D}}$ & 35 \\
\hline 10 & $4-$ & Suzuki & $\mathrm{BMI} \cdot \mathrm{BF}_{4}{ }^{\mathrm{b}}$ & 50 \\
\hline 11 & 4- & Heck & DMF & 100 \\
\hline 12 & $4-^{-}$ & Heck & DMF & 98 \\
\hline 13 & Phl & Heck & DMF & 100 \\
\hline 14 & $\mathrm{PhBr}$ & Heck & DMF & 97 \\
\hline 15 & $4-\mathrm{NO}_{2} \mathrm{Phl}$ & Heck & DMF & 100 \\
\hline 16 & 4- & Heck & DMF & 100 \\
\hline 17 & Phil & Heck & $\mathrm{BMI} \cdot \mathrm{BF}_{4}$ & 10 \\
\hline 18 & 4- & Heck & $\mathrm{BMI} \cdot \mathrm{BF}_{4}{ }^{\mathrm{c}}$ & 40 \\
\hline 19 & PhI & Heck & $\mathrm{BMI} \cdot \mathrm{BF}_{4}{ }^{\mathrm{d}}$ & 54 \\
\hline 20 & 4- & Heck & $\mathrm{BMI} \cdot \mathrm{BF}_{4}$ & 25 \\
\hline
\end{tabular}

"Suzuki conditions:Phenylboronic acid, catalyst 2 (1 mol\%), $\mathrm{K}_{3} \mathrm{PO}_{4}$, 3h, $130^{\circ} \mathrm{C}$; Heck conditions: Styrene, catalyst 2 (1 mol\%), $\mathrm{NaOAc}, 24 \mathrm{~h}, 110^{\circ} \mathrm{C}$. $^{\mathrm{a}}$ with $\mathrm{NBu}_{4} \mathrm{Br}$. ${ }^{b} \mathrm{MeOH}$ added into the reaction. ${ }^{c} 5 \mathrm{~mol} \%$ of catalyst $2 .{ }^{d} 10 \mathrm{~mol} \%$ of catalyst 2.

As depicted from Table 1, it is promising the use of ILs as a media to perform these reactions.

\section{CONCLUSION}

A novel ionically-tagged palladium catalyst was synthesized and successfully applied in the Suzuki and Heck reactions. Furthermore, the use of ILs allows the recovery of catalytic system.

\section{ACKNOWLEDGEMENTS}

Capes, CNPq and FAPDF for partial financial support.

\section{REFERENCES}

Sebesta, R.; Kmentova, I.; Toma, S. Green Chem. 2008, 10, 484-496. 